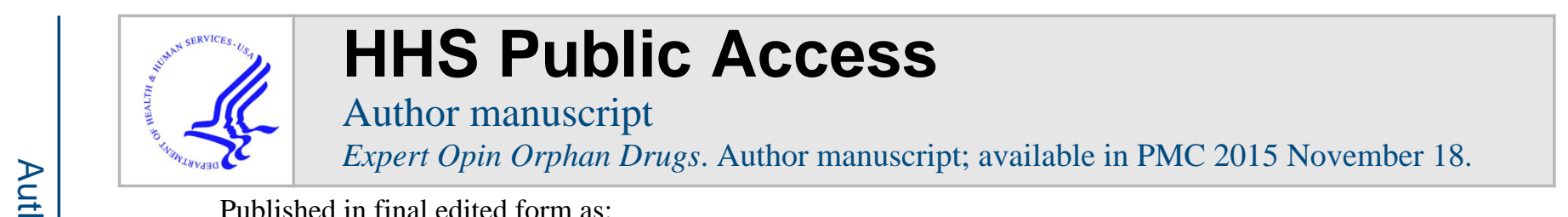

Published in final edited form as:

Expert Opin Orphan Drugs. 2015 ; 3(11): 1255-1266. doi:10.1517/21678707.2015.1088780.

\title{
Gene Therapy for Duchenne muscular dystrophy
}

\author{
Julian Ramos, PhD and Jeffrey S Chamberlain, PhD \\ University of Washington, Wellstone Muscular Dystrophy Research Center, Department of \\ Neurology, Seattle, WA, 98195-7720, USA
}

\section{Abstract}

Introduction-Duchenne muscular dystrophy (DMD) is a relatively common inherited disorder caused by defective expression of the protein dystrophin. The most direct approach to treating this disease would be to restore dystrophin production in muscle. Recent progress has greatly increased the prospects for successful gene therapy of DMD, and here we summarize the most promising developments.

Areas Covered-Gene transfer using vectors derived from adeno-associated virus (AAV) has emerged as a promising method to restore dystrophin production in muscles bodywide, and represents a treatment option applicable to all DMD patients. Using information gleaned from PubMed searches of the literature, attendance at scientific conferences and results from our own lab, we provide an overview of the potential for gene therapy of DMD using AAV vectors including a summary of promising developments and issues that need to be resolved prior to largescale therapeutic implementation.

Expert Opinion-Of the many approaches being pursued to treat DMD and BMD, gene therapy based on AAV-mediated delivery of microdystrophin is the most direct and promising method to treat the cause of the disorder. The major challenges to this approach are ensuring that microdystrophin can be delivered safely and efficiently without eliciting an immune response.

\section{Keywords}

adeno-associated viral (AAV) vectors; Becker muscular dystrophy (BMD); Duchenne muscular dystrophy (DMD); Dystrophin; gene therapy; immune response; micro-dystrophin; microutrophin; tolerization

\section{Introduction}

Mutations in the 2.1 MB dystrophin gene lead to Duchenne and Becker muscular dystrophy (DMD/BMD). The disorder is inherited in an X-linked, recessive pattern and affects approximately one in 3,500-4,000 newborn males worldwide, making it the most common form of muscular dystrophy [1]. While DMD typically results from null-allele mutations that prevent expression of the dystrophin protein, BMD results from mutations that lower expression or that lead to accumulation of an internally truncated protein with reduced stability or functional capacity. Dystrophin deficiency leads to progressive skeletal muscle wasting accompanied by increased fatty and connective tissue, while cardiac muscle displays increasing fibrosis and a progressive dilated cardiomyopathy. Most DMD patients succumb to respiratory or cardiac failure in their $3^{\text {rd }}$ to $4^{\text {th }}$ decade of life. BMD has a later age of onset and slower progression [1]. The recessive nature and slow progression of 
DMD/BMD make them attractive candidates for gene therapies that could restore dystrophin production in affected tissues.

The frequency of DMD arises from a combination of the fact that female carriers are usually asymptomatic and that approximately one third of cases arise from a spontaneous new mutation [2]. Unless there is a family history of DMD, DNA testing for a mutation in the dystrophin gene (DMD in humans, Dmd in mice) is typically not performed in fetal or neonatal screens [3]. DNA testing will ultimately result after a suspected patient exhibits hallmark characteristics [4]. The first symptoms are usually noticeable at 2-4 years of age as the child exhibits difficulty developing at the same physical, and sometimes cognitive, pace as his peers. Approximately 60-65\% of DMD and BMD mutations are deletions [5]. The majority of deletions are found non-randomly throughout middle exons of the gene, while most of the rest are found at the $5^{\prime}$ portion of the gene [6]. This distribution is seen throughout all tested populations and ethnic groups [7]. It is important to note that there is no clear correlation between the location/size of the deletion and the severity and progression of these two allelic disorders [8]. Mutations that disrupt the normal openreading frame of the dystrophin mRNA typically prevent expression of a functional protein, while in-frame deletions can yield stable truncated dystrophins with partial functionality, resulting in the milder BMD [5, 9]. One BMD patient with an in-frame deletion of exons 17-48 has captured much attention for remaining ambulatory into his 70s [10]. This patient was a source of inspiration for engineering mini-dystrophins being developed for gene therapy [11]. When DNA analysis is inconclusive, a muscle biopsy is generally the defining assay. Immunohistochemical staining will determine if any dystrophin is expressed and if it's properly localized at the sarcolemma, while western blot analysis will reveal the size of any dystrophin expressed [12].

\section{Gene replacement therapy for DMD/BMD}

\subsection{Structure and function of dystrophin in muscle}

The design of gene therapies for DMD requires detailed knowledge of the structure and function of the dystrophin protein, which plays a critical role in protecting muscles cells from the forces developed during contraction. This protection derives from an intricate network of protein interactions at specialized sites on the muscle sarcolemma known as costameres. Dystrophin is required to nucleate the assembly of the dystrophin-glycoprotein complex (DGC) at costameres, which links the internal cytoskeleton to the extracellular matrix [13]. The DGC is the major structural component on the sarcolemma that mediates lateral and longitudinal transmission of force from the contractile apparatus to the ECM; it also helps maintain the alignment of sarcomeres in adjacent myofibers [14]. By dissipating the forces of contraction out of myofibers, dystrophin and the DGC protect muscles from contraction-induced injury and thereby help maintain the structural integrity the sarcolemma (Figure 1). Dystrophin restoration, or replacement via gene therapy, therefore requires generation of either a full-length or miniaturized protein able to reassemble the DGC and support a mechanically strong link between the ECM and the cytoskeleton. The DGC also serves as a docking platform for several signaling proteins that aid in maintaining normal muscle homeostasis during contraction $[15,16]$.

Expert Opin Orphan Drugs. Author manuscript; available in PMC 2015 November 18. 
Assembly of the complex is mediated by a variety of distinct structural domains in dystrophin. The major and longest dystrophin isoform, expressed in muscle cells and neurons, is roughly composed of 4 domains, an N-terminal actin-binding domain (ABD), a central rod domain, a cysteine-rich domain and a C-terminal domain [15]. The N-terminal $\mathrm{ABD}$ mediates a direct interaction with F-actin filaments in the subsarcolemmal cytoskeleton. The central rod domain contains 24 'spectrin-like' repeats interspersed with several proline-rich hinge domains. This rod domain is thought to confer flexibility and elasticity to dystrophin allowing it to function during muscle contraction [17]. The rod domain carries a second $\mathrm{ABD}$ and also mediates association with the sarcolemma, with the signaling protein neuronal nitric oxide synthase (nNOS) and with a variety of cytoskeletal proteins including microtubules and intermediate filaments [16, 18-20]. Other dystrophin cytoskeletal interactions are mediated by binding to keratin 19, ankyrin and plectin at the $\mathrm{N}$ and C-terminal regions of dystrophin [16, 19, 21-23]. At the C-terminal end of the rod domain the final hinge joins to the cysteine-rich (CR) domain, and this hinge-CR region forms a binding pocket for the transmembrane protein $\beta$-dystroglycan ( $\beta$-DG) [24]. $\beta$-DG binds a-dystroglycan ( $a-D G$ ) outside the sarcolemma, which binds laminin, the major component of the basal lamina [25-27]. The interactions among the dystroglycans and with dystrophin are strengthened by interactions with the sarcoglycans (SGs), sarcospan (SPN) and a-dystrobrevin (a-DB) [28-31]. The C-terminal domain of dystrophin binds both a-DB and the syntrophins (SYN). While a-DB shares homology with portions of dystrophin and may serve both structural and signaling roles, the syntrophins appear to play primarily signaling roles, in part by mediating the localization of nNOS to the DGC, although they can also localize sodium channels and/or aquaporin to the sarcolemma [32-36].

\subsection{Genetic therapies for DMD/BMD}

Numerous strategies are under development to restore dystrophin production in muscle. These include exon-skipping, protein upregulation, stem cell transplants and mutation suppression, which have been reviewed extensively elsewhere. Here we focus on dystrophin replacement strategies that aim to deliver novel, usually shortened but functional forms of dystrophin to muscle cells. Major challenges for gene replacement of DMD include the enormous size of the gene and protein and the need to deliver a replacement gene to muscles bodywide. While numerous vehicles have been tested for gene replacement, to date the most promising are shuttle vectors derived from adeno-associated virus (AAV). AAV vectors are capable of mediating systemic delivery of new genes to muscles bodywide, have been tested in numerous human clinical trials without serious adverse events and are capable of being prepared in large quantities. The major limitation for DMD is the limited cloning capacity of AAV vectors (approximately $5 \mathrm{~KB}$ ), necessitating the use of miniaturized dystrophin expression cassettes. At high doses AAV vectors have the potential to elicit an immune response against either the AAV capsid or the encoded transgene. Thus, effective delivery strategies may require methods to attenuate this immune response $[37,38]$.

\subsection{Adeno-associated virus: A vehicle for gene therapy}

Adeno-associated virus (AAV) is a member of the parvovirus family and was originally discovered as a contaminant in adenovirus preparations [39].Wild type AAV has a singlestranded DNA genome of $4.7 \mathrm{~Kb}$ that carry rep and cap genes needed for vector DNA 
replication and encapsidation, yet this parvovirus is unable to replicate without the assistance of a helper virus (e.g. adenovirus or herpes virus). The rep and cap genes are dispensable for transduction while the inverted terminal repeats (ITRs) that flank the viral genome are required for genome replication and packaging into the capsid [40]. AAV can be turned into a gene delivery vector by replacing the rep and cap genes with a therapeutic gene expression and encapsidating this recombinant genome. Additionally, AAV displays a very low frequency of integration into the host genome, reducing concerns related to insertional mutagenesis but precluding its utility for stable transduction of muscle stem cells [41-43].

\subsection{Functional, truncated dystrophin isoforms can rescue dystrophic muscle}

Several very mildly affected BMD patients have been found to express small dystrophins that arise from large, internal gene deletion mutations. These observations led to the design and testing of even smaller, so-called 'micro-dystrophins' that can be delivered using AAV vectors, as AAV has only a $\sim 5 \mathrm{~Kb}$ cloning capacity [44]. While some micro-dystrophins display unacceptably low functional activity or stability, others are highly protective against muscle damage and support normal muscle morphology and near normal physiology in mouse and canine models of DMD [45-50]. Several studies indicate that smaller dystrophins are functional even in the presence of other dystrophins, suggesting that they would work for gene therapy of BMD as well as DMD $[51,52]$. A functional connection between the cytoskeletal actin filaments and the integral membrane protein $\beta$-dystroglycan is an essential feature of any dystrophin for both the stability of the protein and to provide mechanical function and enable assembly of the DGC. Truncation of the N-terminal actin-binding domain severely disrupts the stability and function of dystrophin [52-54]. However, the Cterminal domain has been found to be nonessential in mice and humans [55]. Truncation within the dystroglycan-binding domain completely ablated stable assembly of the DGC $[53,56,57]$. Analysis of various in-frame deletions in the rod domain revealed a high degree of functionality and stability even when the deletions removed several spectrin-like repeats (SRs) and internal hinges [58]. However, there is a correlation between the number of SRs and the degree of functionality in skeletal muscle. Dystrophins with less than four SRs exhibit minimal functionality, at best, while those with four or more exhibit varying degrees of functionality $[58,59]$. The critical features of a functional micro-dystrophin are therefore an intact actin-binding domain, at least 4 of the 24 spectrin-like repeats and the dystroglycan-binding domain. Improved micro-dystrophins continue to be developed by selection of specific rod-domain sequences needed for maximal stability, elasticity and DGC restoration.

While the limited carrying capacity of the AAV vector system has driven research on microdystrophins, several studies have explored co-delivering of multiple AAV vectors that enable generation of a larger transcript in muscle cells following homologous recombination or vector concatamirization. This was first demonstrated by co-intravascular delivery of two AAV vectors with a small sequence overlap that directed homologous recombination in target tissues to generate an expression cassette of $7.3 \mathrm{~KB}$ encoding a highly functional "mini-dystrophin" [60]. Several groups expanded on this multi-vector approach by using three vectors to generate the full-length dystrophin cDNA in skeletal muscles of mdx mice

Expert Opin Orphan Drugs. Author manuscript; available in PMC 2015 November 18. 
$[61,62]$. However, the efficiency of this triple vector event was drastically lower compared with the dual vector approaches to generate mini-dystrophins and is limited by several safety factors. First, the multiple vector genomes being delivered form concatamers that can encode aberrant proteins. Secondly, the method requires a doubling or tripling of vector doses needed for gene delivery, raising immunological concerns.

\subsection{AAV delivery of micro-dystrophin for DMD gene therapy}

Effective use of AAV vectors for systemic gene delivery requires infusion of high doses of vector, incorporation of functional expression cassettes that are expressed in striated muscles, and minimal activation of the immune system. A critical threshold concentration of vector particles is needed to achieve extravasation of the vector for systemic delivery via the vasculature [63]. While this precise dose in humans remains to be determined, it varies somewhat depending on which serotype of AAV is used as a source of capsid protein, the delivery route, the strength of the gene regulatory cassette used to drive dystrophin expression and the precise micro-dystrophin cDNA sequence. Animal studies using vectors derived from AAV serotypes 6, 8 and 9 suggest that doses in the range of $10^{14}$ vector genomes per $\mathrm{kg}$ will be needed to achieve effective delivery [63-67]. Off-target effects, such as dystrophin expression in liver can be minimized by the use of muscle-specific regulatory cassettes (RCs) such as those derived from the MCK and desmin genes [68]. Enhanced gene expression on a per genome basis can be increased with stronger RCs and by the use of codon-optimized, and functionally enhanced cDNAs. Within the context of AAV delivery, RC optimization is currently focused on developing small, but powerful cassettes able to function in all muscle fiber types [69].

\subsection{Immune responses to AAV capsid and transgene}

An important concern for gene replacement methods in patients relates to immunological reactions to the dystrophin-expressing vectors. Some patients display pre-existing neutralizing antibodies against various AAV serotypes, which can limit gene transfer efficiency. Patients could also develop a cytotoxic T-cell (CTL) mediated immune response against either the vector or the dystrophin protein following gene transfer that could lead to loss of transgene expression $[37,38]$. The context of which vector type is used, the route of delivery, dose, and signaling responses from innate immune responses can all influence how a naïve T-cell responds to vector infusion (Figure 2). This response can lead to differentiation into effector $\mathrm{T}$ cells able to promote or suppress inflammation and assist with $\mathrm{CD} 8^{+} \mathrm{T}$ cell, B cell and T-regulatory responses [70]. Although effector T cells canonically direct a humoral immune response to viruses, $\mathrm{B}$ cells can also influence naïve and effector $\mathrm{T}$ cells through antigen presentation or their signaling stimuli. B cells can carry out this task either alone or in conjunction with other surrounding stimuli [70, 71]. A multitude of preclinical and clinical studies are revealing various immunological scenarios that face AAV-mediated gene therapy (Figure 3).

The innate immune system has several sets of pathogen recognition receptors (PRRs). The complement system is a set of inactivated enzymes that circulate in the blood or serve as cell receptors awaiting activation by foreign antigens. AAV serotypes 1,2 , and 8 were found to bind complement and their receptors, allowing vector uptake by macrophages and result in

Expert Opin Orphan Drugs. Author manuscript; available in PMC 2015 November 18. 
innate signaling response and eventual humoral response [72]. Another set of PRRs is the Toll-like receptors (TLRs), which reside at the membrane or in endosomes. The endosomal TLR9 recognizes unmethylated cytosine guanine dinucleotide motifs that are prevalent in DNA originating from viruses or bacteria, but not in mammalian DNA. Current good manufacturing practices in AAV viral generation uses vector plasmids grown from bacterial cultures [73], leaving an inherit risk of using unmethylated AAV vectors.

Unmethylated CpG AAV vector genomes have been recognized by TLR9 in conventional (bone marrow-derived) dendritic cells (cDCs) and plasmacytoid dendritic cells (pDCs), neutrophils, macrophages, and natural killer cells [74, 75]. TLR9 activation signaling is mediated through adaptor protein myeloid differentiation primary response 88 , or MyD88, and leads to type I interferon (IFN- $\alpha / \beta$ ) production. Although many cell types can produce these antiviral proteins, $\mathrm{pDC}$ are a major source of IFN- $\alpha / \beta[76,77]$. The $\mathrm{pDCs}$ ' increased responsiveness to TRL9-MyD88 signaling over cDCs [74] reinforces their active role in AAV immunity. This interferon response activates naïve $\mathrm{CD} 8^{+} \mathrm{T}$ cells for cross-priming, where extracellular antigens are presented to them. However, pDCs cannot present exogenous antigens to $\mathrm{CD}^{+} \mathrm{T}$ cells but can present endogenous antigens [78]. The ability of AAV to transfect pDCs $[74,79]$ can cause CpG-activation and enable them to prime functional $\mathrm{CD}^{+} \mathrm{T}$ cells, resulting in a CTL response. AAV capsid and transgene-specific responses by effector $\mathrm{CD}^{+}$cells has been reported in multiple animal models and in humans [37, 38, 79-86]. Removing most CpG motifs in the vector genome between the inverted terminal repeats (ITRs) reduced $\mathrm{CD}^{+} \mathrm{T}$ cell response and production of interferongamma (INF- $\gamma$ ) [87]. However, CpGs were not removed from the ITRs, and it remains unknown if this removal will affect vector genome packaging and transduction.

Canonical generation of an effector $\mathrm{CD}^{+} \mathrm{T}$ cell involves a helper $\mathrm{CD} 4^{+} \mathrm{T}$ cell to activate, or license, the antigen presented to it by a third party antigen presenting cell. This process relies on co-stimulatory molecules expressed by the interacting cells, including CD40 and CD40 ligand (CD40L) [70, 71]. Dendritic cells transduced with AAV2 were unable to produce a CTL response when adoptively transferred into CD40L null mice [79]. $\mathrm{CD}^{+} \mathrm{T}$ cell responses to AAV serotypes 8 and rh32.33 were attenuated when $\mathrm{CD}^{+}{ }^{+} \mathrm{T}$ cells were ablated [88]. Yet, initial responses of these two T cell populations to AAV, and viruses in general, are bidirectional and are further influenced by preceding stimuli from the innate immunity. $\mathrm{CD}^{+} \mathrm{T}$ cell priming can occur without $\mathrm{CD}^{+} \mathrm{T}$ cell help or CD40/CD40L interaction and instead rely on direct stimulation from DCs with type I interferons [89]. IFN$\alpha / \beta$, along with interleukin- 12 , can activate $\mathrm{CD}^{+} \mathrm{T}$ cells to produce IFN- $\gamma[74,90]$. IFN- $\gamma$ is one of the signature cytokines that drives naïve $\mathrm{CD}^{+}{ }^{+} \mathrm{T}$ cells to become effector $\mathrm{T}$ helper type $1\left(\mathrm{~T}_{\mathrm{H}} 1\right)$ cells, which are characterized by IFN- $\gamma$ production [91]. This creates a feedforward mechanism to further commit other naïve $\mathrm{CD}^{+}{ }^{+} \mathrm{T}$ cells towards the $\mathrm{T}_{\mathrm{H}} 1$ subset. $\mathrm{T}_{\mathrm{H}} 1$ cells create a pro-inflammatory response, activate macrophages, and influences what type of neutralizing antibodies $\mathrm{B}$ cells produce $[70,71]$.

During viral infection, the spleen and lymph nodes develop sites called germinal centers where B cells can mature, switch immunoglobulin (Ig) isotype production, and become Igsecreting plasma cells [92]. Activated B cells secrete IgM as an initial reaction to infection that is independent of $\mathrm{T}$ cell influence. During the course of infection, $\mathrm{T}$ helper $\left(\mathrm{T}_{\mathrm{H}}\right)$ cells 
travel to the spleen and lymph nodes to aid in germinal center formation. Within these specialized structures, $\mathrm{T}_{\mathrm{H}}$ cells interact with B cells and influence their maturation and Ig class switching. Anti-viral antibody responses in mice are predominately $\operatorname{IgG} 2 \mathrm{a}$ and are characteristic of a $\mathrm{T}_{\mathrm{H}} 1$ cell-driven humoral response [93]. B cells producing IgG1 neutralizing antibodies are characteristic of a $\mathrm{T}_{\mathrm{H}} 2$ cell response [91]. Murine neutralizing antibody responses to several AAV serotypes, including 1 and 2, are predominately of the IgG2 class when administered intramuscularly or intravenously [94-96]. However, humans intramuscularly administered AAV serotypes 1 or 2 had a prevalent $\operatorname{IgG} 1$ antibody response, although $\mathrm{IgG} 2$ as well as $\mathrm{T}$ cell-independent $\mathrm{IgG} 3$ antibodies also increased [97, 98]. The range in neutralizing antibody isotypes against AAV in both animal models and humans indicates that multiple $\mathrm{T}_{\mathrm{H}}$ cell subsets provide help to B cells. Intravascular administration is the most clinically feasible route of administration. Since the lymphoid system and circulatory system are intertwined, an immune response to both the AAV capsid and vector seems unavoidable unless precautions are taken to modulate the immune system.

All patients will likely develop B- and possibly T-cell immune responses against the vector that could preclude re-treatment unless steps are taken to prevent vaccination against the gene delivery vehicle. There is also evidence that the dystrophin protein (full-length or micro-dystrophin) can be recognized as a foreign antigen. This has been reported by a variety of experimental strategies including cell therapy transplantation studies [99, 100], adenovirus vector [101], and AAV vector delivery [37]. Fortunately, a variety of approaches can be taken either before or after gene transfer to limit or prevent such immune responses. In the case of pre-existing immunity against $\mathrm{AAV}$ one might be able to select a vector serotype that is not neutralized by the patient's serum, as many different serotypes of AAV have been described. Another approach might be to use plasmaphoresis to reduce the levels of neutralizing antibodies prior to vector infusion [102]. In either case, successful gene transfer would expose the patient's immune system to the newly delivered vector and/or transgene, generating B- and T-cell responses that could limit the ability to readminister vector. Of greater immediate concern is the possibility of generating a CTL response that could destroy successfully transduced muscle cells. Such T-cell responses against vector and possibly transgene have been observed in several animal studies and in human clinical trials [37, 103, 104]. T-cell reactivity against the AAV vector has been successfully blocked or limited by transient immune suppression, by the use of muscle-restricted promoters and by high dose treatment with corticosteroids $[68,69,103,104]$. However, the ability to block cellular and humoral immunity sufficiently to allow vector readministration years after the initial treatment may require blockade of CD4 and/or CD8 T-cell recognition of vector and transgene, and might be aided by activation of T-regulatory cells or by direct induction of tolerance against the transgene [105-109]. An alternate approach to avoiding an immune response against dystrophin would be to deliver a functional surrogate that would not be recognized as a foreign antigen, such as micro-utrophin [110].

\section{Expert opinion}

Gene therapy for DMD/BMD is showing tremendous potential to halt dystrophic progression and restore or maintain muscle function and quality of life in patients. Of the various methods being developed for therapy, dystrophin replacement represents the most 
direct method to treat the cause of the disorder, which is due to lost or impaired dystrophin expression. AAV-vector mediated delivery of micro-dystrophin appears to be the most direct way to restore dystrophin expression in muscles, and could lead to a long-lasting treatment. The advantages of this system include an ability to deliver genes to skeletal and cardiac muscles bodywide, the ability of optimized micro-dystrophins to halt muscle degeneration and at least partially reverse pre-existing pathophysiological abnormalities, the safety profile of AAV vectors seen to date in human clinical trials, and the effectiveness of mini/micro-dystrophins even in the presence of exogenous, partially functional dystrophins (i.e. in BMD models) [51].

Nonetheless, before this approach can be applied routinely it will be necessary to ensure that vectors can be delivered at high doses safely and efficiently without eliciting an immune response that could lead to loss of transgene expression. Further, since AAV vectors exist within cells as non-integrated episomes, delivery must be performed in such a way as to allow readministration years after the initial infusion, as vector copies will likely be lost due to normal muscle cell turnover. Normal skeletal myofibers turnover at a very slow rate, likely with a half-life of years, although exercise can cause muscle damage and lead to focal degeneration and regeneration. Cardiomyocytes appear much more long lasting than skeletal myofibers such that dystrophin expression might be longer lasting in the heart. While microdystrophins are highly functional, development of improved versions of these proteins would likely further increase the efficacy of AAV-mediated gene therapy. Also, current methods have not shown a high degree of smooth muscle targeting, leading to concerns that subtle smooth muscle pathologies could become more prominent in older, AAV-treated patients. The use of novel of engineered AAV vector serotypes could potentially be used to increase smooth muscle targeting, as well as might be a way to avoid neutralizing activity within patient serum. Recent results in animal models of DMD and in human trials for other genetic disorders suggest that all of these potential obstacles can be overcome and that gene therapy approaches may soon lead to an effective treatment for DMD/BMD and other forms of muscular dystrophy.

\section{Bibliography}

Papers of special note have been highlighted as either of interest $(\bullet)$ or of considerable interest $(\bullet)$ to readers.

1. Emery, AEH. Duchenne muscular dystrophy. 3rd. Oxford, New York: Oxford University Press; 2003.

2. Davie AM, Emery AE. Estimation of proportion of new mutants among cases of Duchenne muscular dystrophy. J Med Genet. 1978; 15:339-45. [PubMed: 739522]

3. Darras BT, Blattner P, Harper JF, et al. Intragenic deletions in 21 Duchenne muscular dystrophy (DMD)/Becker muscular dystrophy (BMD) families studied with the dystrophin cDNA: location of breakpoints on HindIII and BglII exon-containing fragment maps, meiotic and mitotic origin of the mutations. Am J Hum Genet. 1988; 43:620-9. [PubMed: 2903663]

4. Darras BT, Jones HR. Diagnosis of pediatric neuromuscular disorders in the era of DNA analysis. Ped Neurol. 2000; 23:289-300.

5. Koenig M, Beggs AH, Moyer M, et al. The molecular basis for Duchenne versus Becker muscular dystrophy: correlation of severity with type of deletion. Am J Hum Genet. 1989; 45:498-506. [PubMed: 2491009] 
6. Chamberlain JS, Grant SG, Reeves AA, et al. Regional localization of the murine Duchenne muscular dystrophy gene on the mouse X chromosome. Somat Cell Molec Genet. 1987; 13:671-8. [PubMed: 2890215]

7. Chamberlain JS, Chamberlain JR, Fenwick RG, et al. Diagnosis of Duchenne and Becker muscular dystrophies by polymerase chain reaction: A multicenter study. JAMA. 1992; 267:2609-15. [PubMed: 1573747]

8. Monaco AP, Bertelson CJ, Liechti-Gallati S, et al. An explanation for the phenotypic differences between patients bearing partial deletions of the DMD locus. Genomics. 1988; 2:90-5. [PubMed: 3384440]

9. Baumbach LL, Chamberlain JS, Ward PA, et al. Molecular and clinical correlations of deletions leading to Duchenne and Becker muscular dystrophies. Neurology. 1989; 39:465-74. [PubMed: 2927671]

10. England SB, Nicholson LV, Johnson MA, et al. Very mild muscular dystrophy associated with the deletion of 46\% of dystrophin. Nature. 1990; 343:180-2. [PubMed: 2404210]

11. Phelps SF, Hauser MA, Cole NM, et al. Expression of full-length and truncated dystrophin minigenes in transgenic mdx mice. Hum Molec Genet. 1995; 4:1251-8. [PubMed: 7581361]

12. Hoffman EP, Fischbeck KH, Brown RH, et al. Characterization of dystrophin in muscle-biopsy specimens from patients with Duchenne's or Becker's muscular dystrophy. N Engl J Med. 1988; 318:1363-8. [PubMed: 3285207]

13. Ervasti, JM. Structure and function of the dystrophin-glycoprotein complex. In: Winder, SJ., editor. Molecular Mechanisms of Muscular Dystrophies. Georgetown: Landes Biosciences; 2006. p. 1-13.

14. Ramaswamy KS, Palmer ML, van der Meulen JH, et al. Lateral transmission of force is impaired in skeletal muscles of dystrophic mice and very old rats. J Physiol. 2011; 589:1195-208. [PubMed: 21224224]

15. Abmayr, S.; Chamberlain, J. The structure and function of dystrophin. In: Winder, SJ., editor. Molecular Mechanisms of Muscular Dystrophies. Georgetown: Landes Biosciences; 2006. p. 14-34.

16. Lai Y, Thomas GD, Yue Y, et al. Dystrophins carrying spectrin-like repeats 16 and 17 anchor nNOS to the sarcolemma and enhance exercise performance in a mouse model of muscular dystrophy. J Clin Invest. 2009; 119:624-35. [PubMed: 19229108]

17. Winder SJ. The membrane-cytoskeleton interface: the role of dystrophin and utrophin. J Mus Res Cell Motil. 1997; 18:617-29.

18. Lai Y, Zhao J, Yue Y, Duan D. alpha2 and alpha3 helices of dystrophin R16 and R17 frame a microdomain in the alpha1 helix of dystrophin R17 for neuronal NOS binding. PNAS. 2013; 110:525-30. [PubMed: 23185009]

19. Prins KW, Humston JL, Mehta A, et al. Dystrophin is a microtubule-associated protein. The J Cell Biol. 2009; 186:363-9. [PubMed: 19651889]

20. Bhosle RC, Michele DE, Campbell KP, et al. Interactions of intermediate filament protein synemin with dystrophin and utrophin. Biochem Biophys Res Commun. 2006; 346:768-77. [PubMed: 16777071]

21. Stone MR, O’Neill A, Catino D, Bloch RJ. Specific interaction of the actin-binding domain of dystrophin with intermediate filaments containing keratin 19. Mol Biol Cell. 2005; 16:4280-93. [PubMed: 16000376]

22. Rezniczek GA, Konieczny P, Nikolic B, et al. Plectin 1f scaffolding at the sarcolemma of dystrophic (mdx) muscle fibers through multiple interactions with beta-dystroglycan. J Cell Biol. 2007; 176:965-77. [PubMed: 17389230]

23. Ayalon G, Davis JQ, Scotland PB, Bennett V. An ankyrin-based mechanism for functional organization of dystrophin and dystroglycan. Cell. 2008; 135:1189-200. [PubMed: 19109891]

24. Ishikawa-Sakurai M, Yoshida M, Imamura M, et al. ZZ domain is essentially required for the physiological binding of dystrophin and utrophin to beta-dystroglycan. Hum Molec Genet. 2004; 13:693-702. [PubMed: 14962982]

25. Ozawa E, Nishino I, Nonaka I. Sarcolemmopathy: muscular dystrophies with cell membrane defects. Brain Pathol. 2001; 11:218-30. [PubMed: 11303797] 
26. Ibraghimov-Beskrovnaya O, Ervasti JM, Leveille CJ, et al. Primary structure of dystrophinassociated glycoproteins linking dystrophin to the extracellular matrix. Nature. 1992; 355:696702. [PubMed: 1741056]

27. Burkin DJ, Kaufman SJ. The alpha7beta1 integrin in muscle development and disease. Cell Tiss Res. 1999; 296:183-90.

28. Noguchi S, Wakabayashi E, Imamura M, et al. Developmental expression of sarcoglycan gene products in cultured myocytes. Biochem Biophys Res Commun. 1999; 262:88-93. [PubMed: 10448073]

29. Sakamoto A, Ono K, Abe M, et al. Both hypertrophic and dilated cardiomyopathies are caused by mutation of the same gene, delta-sarcoglycan, in hamster: an animal model of disrupted dystrophin-associated glycoprotein complex. PNAS. 1997; 94:13873-8. [PubMed: 9391120]

30. Crosbie RH, Heighway J, Venzke DP, et al. Sarcospan, the 25-kDa transmembrane component of the dystrophin-glycoprotein complex. J Biol Chem. 1997; 272:31221-4. [PubMed: 9395445]

31. Marshall JL, Crosbie-Watson RH. Sarcospan: a small protein with large potential for Duchenne muscular dystrophy. Skel Mus. 2013; 3:1.

32. Crosbie RH, Dovico SA, Flanagan JD, et al. Characterization of aquaporin-4 in muscle and muscular dystrophy. FASEB J. 2002; 16:943-9. [PubMed: 12087055]

33. Grady RM, Grange RW, Lau KS, et al. Role for alpha-dystrobrevin in the pathogenesis of dystrophin-dependent muscular dystrophies. Nat Cell Biol. 1999; 1:215-20. [PubMed: 10559919]

34. Adams ME, Kramarcy N, Krall SP, et al. Absence of alpha-syntrophin leads to structurally aberrant neuromuscular synapses deficient in utrophin. J Cell Biol. 2000; 150:1385-98. [PubMed: 10995443]

35. Kameya S, Miyagoe Y, Nonaka I, et al. alpha1-syntrophin gene disruption results in the absence of neuronal-type nitric-oxide synthase at the sarcolemma but does not induce muscle degeneration. $\mathrm{J}$ Biol Chem. 1999; 274:2193-200. [PubMed: 9890982]

36. Adams ME, Tesch Y, Percival JM, et al. Differential targeting of nNOS and AQP4 to dystrophindeficient sarcolemma by membrane-directed alpha-dystrobrevin. J Cell Sci. 2008; 121:48-54. [PubMed: 18057022]

37••. Mendell JR, Campbell K, Rodino-Klapac L, et al. Dystrophin immunity in Duchenne's muscular dystrophy. New Engl J Med. 2010; 363:1429-37. First human gene therapy trial for DMD, where AAV vectors were used to deliver a micro-dystrophin cassette. While sustained gene expression was not achieved, the results highlighted the issues related to transgene and vector immune responses. [PubMed: 20925545]

38. Mays LE, Wilson JM. The complex and evolving story of T cell activation to AAV vector-encoded transgene products. Mol Ther. 2011; 19:16-27. [PubMed: 21119617]

39. Atchison RW, Casto BC, Hammon WM. Adenovirus-Associated Defective Virus Particles. Science. 1965; 149:754-6. [PubMed: 14325163]

40. McLaughlin SK, Collis P, Hermonat PL, Muzyczka N. Adeno-associated virus general transduction vectors: analysis of proviral structures. J Virol. 1988; 62:1963-73. [PubMed: 2835501]

41. Inagaki K, Lewis SM, Wu X, et al. DNA palindromes with a modest arm length of greater, similar 20 base pairs are a significant target for recombinant adeno-associated virus vector integration in the liver, muscles, and heart in mice. J Virol. 2007; 81:11290-303. [PubMed: 17686840]

42. Nakai H, Montini E, Fuess S, et al. AAV serotype 2 vectors preferentially integrate into active genes in mice. Nature Genet. 2003; 34:297-302. [PubMed: 12778174]

43. Arnett LHA, Konieczny P, Ramos JN, et al. Adeno-associated viral vectors do not efficiently target muscle satellite cells. Mol Ther - Meth Clin Develop. 2014; 1:14038. First detailed study of the ability of AAV vectors to transduce muscle satellite cells. The results showed that AAV vectors are not stably retained in satellite cells, precluding their use in gene replacement strategies targeting stem cells.

44••. Harper SQ, Hauser MA, DelloRusso C, et al. Modular flexibility of dystrophin: Implications for gene therapy of Duchenne muscular dystrophy. Nat Med. 2002; 8:253-61. Analysis of the function of various mini- and micro-dystrophins. This study outlined many features of dystrophin structure important for AAV-mediated gene therapy. [PubMed: 11875496] 
45. Yue Y, Li Z, Harper SQ, et al. Microdystrophin gene therapy of cardiomyopathy restores dystrophin-glycoprotein complex and improves sarcolemma integrity in the mdx mouse heart. Circulation. 2003; 108:1626-32. [PubMed: 12952841]

46. Wang Z, Storb R, Halbert CL, et al. Successful regional delivery and long-term expression of a dystrophin gene in canine muscular dystrophy: a preclinical model for human therapies. Mol Ther. 2012; 20:1501-7. [PubMed: 22692496]

47. Townsend D, Blankinship MJ, Allen JM, et al. Systemic administration of micro-dystrophin restores cardiac geometry and prevents dobutamine-induced cardiac pump failure. Mol Ther. 2007; 15:1086-92. [PubMed: 17440445]

48. Gregorevic P, Allen JM, Minami E, et al. rAAV6-microdystrophin preserves muscle function and extends lifespan in severely dystrophic mice. Nat Med. 2006; 12:787-9. [PubMed: 16819550]

49. Bostick B, Yue Y, Lai Y, et al. Adeno-associated virus serotype-9 microdystrophin gene therapy ameliorates electrocardiographic abnormalities in mdx mice. Hum Gene Ther. 2008; 19:851-7. [PubMed: 18666839]

50. Shin JH, Pan X, Hakim CH, et al. Microdystrophin ameliorates muscular dystrophy in the canine model of Duchenne muscular dystrophy. Mol Ther. 2013; 21:750-7. [PubMed: 23319056]

51. Crawford GE, Lu QL, Partridge TA, Chamberlain JS. Suppression of revertant fibers in mdx mice by expression of a functional dystrophin. Hum Mol Genet. 2001; 10:2745-50. [PubMed: 11734539]

52. Warner LE, DelloRusso C, Crawford RW, et al. Expression of Dp260 in muscle tethers the actin cytoskeleton to the dystrophin-glycoprotein complex and partially prevents dystrophy. Hum Mol Genet. 2002; 11:1095-105. [PubMed: 11978768]

53. Corrado K, Rafael JA, Mills PL, et al. Transgenic mdx mice expressing dystrophin with a deletion in the actin-binding domain display a "mild Becker" phenotype. J Cell Biol. 1996; 134:873-84. [PubMed: 8769413]

54. Banks GB, Gregorevic P, Allen JM, et al. Functional capacity of dystrophins carrying deletions in the N-terminal actin-binding domain. Hum Mol Genet. 2007; 16:2105-13. [PubMed: 17588958]

55. McCabe ER, Towbin J, Chamberlain J, et al. Complementary DNA probes for the Duchenne muscular dystrophy locus demonstrate a previously undetectable deletion in a patient with dystrophic myopathy, glycerol kinase deficiency, and congenital adrenal hypoplasia. The J Clin Invest. 1989; 83:95-9. [PubMed: 2536049]

56. Koenig M, Beggs AH, Moyer M, et al. The molecular basis for Duchenne versus Becker muscular dystrophy: correlation of severity with type of deletion. Amer J Hum Genet. 1989; 45:498-506. [PubMed: 2491009]

57. Beggs AH, Hoffman EP, Snyder JR, et al. Exploring the molecular basis for variability among patients with Becker muscular dystrophy: dystrophin gene and protein studies. Amer J Hum Genet. 1991; 49:54-67. [PubMed: 2063877]

58. Harper SQ, Hauser MA, DelloRusso C, et al. Modular flexibility of dystrophin: implications for gene therapy of Duchenne muscular dystrophy. Nature Med. 2002; 8:253-61. [PubMed: 11875496]

59. Wang B, Li J, Xiao X. Adeno-associated virus vector carrying human minidystrophin genes effectively ameliorates muscular dystrophy in mdx mouse model. PNAS. 2000; 97:13714-9. [PubMed: 11095710]

60. Odom GL, Gregorevic P, Allen JM, Chamberlain JS. Gene therapy of mdx mice with large truncated dystrophins generated by recombination using rAAV6. Mol Ther. 2011; 19:36-45. [PubMed: 20859263]

61. Lostal W, Kodippili K, Yue Y, Duan D. Full-Length Dystrophin Reconstitution with AdenoAssociated Viral Vectors. Hum Gene Ther. 2014

62. Koo T, Popplewell L, Athanasopoulos T, Dickson G. Triple trans-splicing adeno-associated virus vectors capable of transferring the coding sequence for full-length dystrophin protein into dystrophic mice. Hum Gene Ther. 2014; 25:98-108. [PubMed: 24191945]

63••. Gregorevic P, Blankinship MJ, Allen JM, et al. Systemic delivery of genes to striated muscles using adeno-associated viral vectors. Nat Med. 2004; 10:828-34. Demonstration that AAV vectors could be used to achieve systemic delivery of new genes to muscles. This study laid the 
groundwork for current efforts to treat the muscular dystrophies using AAV vector delivery. [PubMed: 15273747]

64-. Le Guiner C, Montus M, Servais L, et al. Forelimb treatment in a large cohort of dystrophic dogs supports delivery of a recombinant AAV for exon skipping in Duchenne patients. Mol Ther. 2014; 22:1923-35. Successful regional limb delivery of an AAV vector to dystrophic dogs. The results showed that dystrophin expression could be partially restored by delivery of a U7-driven exon skipping cassette. [PubMed: 25200009]

65. Yue Y, Ghosh A, Long C, et al. A single intravenous injection of adeno-associated virus serotype-9 leads to whole body skeletal muscle transduction in dogs. Mol Ther. 2008; 16:1944-52. [PubMed: 18827804]

66. Kornegay JN, Li J, Bogan JR, et al. Widespread muscle expression of an AAV9 human minidystrophin vector after intravenous injection in neonatal dystrophin-deficient dogs. Mol Ther. 2010; 18:1501-8. [PubMed: 20517298]

67. Pan X, Yue Y, Zhang K, et al. Long-term robust myocardial transduction of the dog heart from a peripheral vein by adeno-associated virus serotype-8. Hum Gene Ther. 2013; 24:584-94. [PubMed: 23551085]

68. Salva MZ, Himeda CL, Tai PW, et al. Design of tissue-specific regulatory cassettes for high-level rAAV-mediated expression in skeletal and cardiac muscle. Mol Ther. 2007; 15:320-9. [PubMed: 17235310]

69. Tai PW, Smith CL, Angello JC, Hauschka SD. Analysis of fiber-type differences in reporter gene expression of beta-gal transgenic muscle. Meth Mol Biol. 2012; 798:445-59.

70. Swain SL, McKinstry KK, Strutt TM. Expanding roles for CD4(+) T cells in immunity to viruses. Nature Rev Immunol. 2012; 12:136-48. [PubMed: 22266691]

71. Lund FE, Randall TD. Effector and regulatory B cells: modulators of CD4+ T cell immunity. Nature reviews Immunology. 2010; 10:236-47.

72. Zaiss AK, Cotter MJ, White LR, et al. Complement is an essential component of the immune response to adeno-associated virus vectors. J Virol. 2008; 82:2727-40. [PubMed: 18199646]

73. Wright JF, Wellman J, High KA. Manufacturing and regulatory strategies for clinical AAV2hRPE65. Current gene therapy. 2010; 10:341-9. [PubMed: 20712582]

74. Zhu J, Huang X, Yang Y. The TLR9-MyD88 pathway is critical for adaptive immune responses to adeno-associated virus gene therapy vectors in mice. J Clin Invest. 2009; 119:2388-98. [PubMed: 19587448]

75. Martino AT, Suzuki M, Markusic DM, et al. The genome of self-complementary adeno-associated viral vectors increases Toll-like receptor 9-dependent innate immune responses in the liver. Blood. 2011; 117:6459-68. [PubMed: 21474674]

76. Siegal FP. The nature of the principal type 1 interferon-producing cells in human blood. Science. 1999; 284:1835-7. [PubMed: 10364556]

77. Coccia EM, Severa M, Giacomini E, et al. Viral infection and Toll-like receptor agonists induce a differential expression of type I and lambda interferons in human plasmacytoid and monocytederived dendritic cells. European J Immunol. 2004; 34:796-805. [PubMed: 14991609]

78. Salio M, Palmowski MJ, Atzberger A, et al. CpG-matured murine plasmacytoid dendritic cells are capable of in vivo priming of functional CD8 T cell responses to endogenous but not exogenous antigens. J Exp Med. 2004; 199:567-79. [PubMed: 14970182]

79. Zhang Y, Chirmule N, Gao Gp, Wilson J. CD40 Ligand-dependent activation of cytotoxic T lymphocytes by adeno-associated virus vectors in vivo: role of immature dendritic cells. J Virol. 2000; 74:8003-10. [PubMed: 10933709]

80. Vandenberghe LH, Wang L, Somanathan S, et al. Heparin binding directs activation of T cells against adeno-associated virus serotype 2 capsid. Nat Med. 2006; 12:967-71. [PubMed: 16845388]

81. Pien GC, Basner-Tschakarjan E, Hui DJ, et al. Capsid antigen presentation flags human hepatocytes for destruction after transduction by adeno-associated viral vectors. J Clin Inv. 2009; 119:1688-95. 
82. Li H, Tuyishime S, Wu TL, et al. Adeno-associated virus vectors serotype 2 induce prolonged proliferation of capsid-specific CD8+ T cells in mice. Mol Ther. 2011; 19:536-46. [PubMed: 21157435]

83. Li H, Lasaro MO, Jia B, et al. Capsid-specific T-cell responses to natural infections with adenoassociated viruses in humans differ from those of nonhuman primates. Mol Ther. 2011; 19:202130. [PubMed: 21587208]

84. Wang Z, Tapscott SJ, Chamberlain JS, Storb R. Immunity and AAV-mediated gene therapy for muscular dystrophies in large animal models and human trials. Front Microbiol. 2011; 2:201. [PubMed: 21980317]

85. Mendell JR, Rodino-Klapac LR, Rosales XQ, et al. Sustained alpha-sarcoglycan gene expression after gene transfer in limb-girdle muscular dystrophy, type 2D. Annals Neurol. 2010; 68:629-38

86. Rogers GL, Martino AT, Aslanidi GV, et al. Innate Immune Responses to AAV Vectors. Front Microbiol. 2011; 2:194. [PubMed: 21954398]

87. Faust SM, Bell P, Cutler BJ, et al. CpG-depleted adeno-associated virus vectors evade immune detection. J Clin Inv. 2013; 123:2994-3001.

88. Mays LE, Vandenberghe LH, Xiao R, et al. Adeno-associated virus capsid structure drives CD4dependent CD8+ T cell response to vector encoded proteins. J Immunol. 2009; 182:6051-60. [PubMed: 19414756]

89. Le Bon A, Etchart N, Rossmann C, et al. Cross-priming of CD8+ T cells stimulated by virusinduced type I interferon. Nature Immunol. 2003; 4:1009-15. [PubMed: 14502286]

90. Cousens LP, Peterson R, Hsu S, et al. Two roads diverged: interferon alpha/beta- and interleukin 12-mediated pathways in promoting $\mathrm{T}$ cell interferon gamma responses during viral infection. $\mathrm{J}$ Exp Med. 1999; 189:1315-28. [PubMed: 10209048]

91. Mosmann TR, Cherwinski H, Bond MW, et al. Two types of murine helper T cell clone. I. Definition according to profiles of lymphokine activities and secreted proteins. J Immunol. 1986; 136:2348-57. [PubMed: 2419430]

92. Dorner T, Radbruch A. Antibodies and B cell memory in viral immunity. Immunity. 2007; 27:38492. [PubMed: 17892847]

93. Coutelier JP, van der Logt JT, Heessen FW, et al. IgG2a restriction of murine antibodies elicited by viral infections. J Exp Med. 1987; 165:64-9. [PubMed: 3794607]

94. Xiao W, Chirmule N, Schnell MA, et al. Route of administration determines induction of T-cellindependent humoral responses to adeno-associated virus vectors. Mol Ther. 2000; 1:323-9. [PubMed: 10933950]

95. Chirmule N, Xiao W, Truneh A, et al. Humoral immunity to adeno-associated virus type 2 vectors following administration to murine and nonhuman primate muscle. J Virol. 2000; 74:2420-5. [PubMed: 10666273]

96. Sudres M, Cire S, Vasseur V, et al. MyD88 signaling in B cells regulates the production of Th1dependent antibodies to AAV. Mol Ther. 2012; 20:1571-81. [PubMed: 22643865]

97. Murphy SL, Li H, Mingozzi F, et al. Diverse IgG subclass responses to adeno-associated virus infection and vector administration. J Med Virol. 2009; 81:65-74. [PubMed: 19031458]

98. Mingozzi F, Meulenberg JJ, Hui DJ, et al. AAV-1-mediated gene transfer to skeletal muscle in humans results in dose-dependent activation of capsid-specific T cells. Blood. 2009; 114:2077-86. [PubMed: 19506302]

99. Huard J, Roy R, Bouchard JP, et al. Human myoblast transplantation between immunohistocompatible donors and recipients produces immune reactions. Transplantation proceedings. 1992; 24:3049-51. [PubMed: 1466052]

100. Ohtsuka Y, Udaka K, Yamashiro Y, et al. Dystrophin acts as a transplantation rejection antigen in dystrophin-deficient mice: implication for gene therapy. J Immunol. 1998; 160:4635-40. [PubMed: 9574572]

101. Gilchrist SC, Ontell MP, Kochanek S, Clemens PR. Immune response to full-length dystrophin delivered to Dmd muscle by a high-capacity adenoviral vector. Mol Ther. 2002; 6:359-68. [PubMed: 12231172]

102. Chicoine LG, Montgomery CL, Bremer WG, et al. Plasmapheresis eliminates the negative impact of AAV antibodies on microdystrophin gene expression following vascular delivery. Mol 
Ther. 2014; 22:338-47. Application of plasmaphoresis to reduce neutralizing antibody titers against AAV. This approach could impportant to allow vector adminsitration to patients with prior exposure to AAV. [PubMed: 24196577]

103••. Nathwani AC, Reiss UM, Tuddenham EG, et al. Long-term safety and efficacy of factor IX gene therapy in hemophilia B. N Engl J Med. 2014; 371:1994-2004. Successful gene delivery and long-term expression of clotting Factor IX in hemophilia b patients using AAV vectors. Several patients expressed therapeutic levels of Factor IX, although the use of transient immune system blockade was needed to sustain expression. [PubMed: 25409372]

104. Wang Z, Kuhr CS, Allen JM, et al. Sustained AAV-mediated dystrophin expression in a canine model of Duchenne muscular dystrophy with a brief course of immunosuppression. Mol Ther. 2007; 15:1160-6. [PubMed: 17426713]

105. Lorain S, Gross DA, Goyenvalle A, et al. Transient immunomodulation allows repeated injections of AAV1 and correction of muscular dystrophy in multiple muscles. Mol Ther. 2008; 16:541-7. [PubMed: 18180780]

106. Manning WC, Zhou S, Bland MP, et al. Transient immunosuppression allows transgene expression following readministration of adeno-associated viral vectors. Hum Gene Ther. 1998; 9:477-85. [PubMed: 9525309]

107•. Halbert CL, Standaert TA, Wilson CB, Miller AD. Successful readministration of adenoassociated virus vectors to the mouse lung requires transient immunosuppression during the initial exposure. J Virol. 1998; 72:9795-805. First demonstration that AAV vectors could be readministrated ONLY if the initial immune response to the vectors was blocked. [PubMed: 9811715]

108. McIntosh JH, Cochrane M, Cobbold S, et al. Successful attenuation of humoral immunity to viral capsid and transgenic protein following AAV-mediated gene transfer with a non-depleting CD4 antibody and cyclosporine. Gene Ther. 2012; 19:78-85. [PubMed: 21716299]

109. Roep BO, Solvason N, Gottlieb PA, et al. Plasmid-encoded proinsulin preserves C-peptide while specifically reducing proinsulin-specific CD8+ T cells in type 1 diabetes. Sci Transl Med. 2013; 5:191ra82.

110. Odom GL, Gregorevic P, Allen JM, et al. Microutrophin delivery through rAAV6 increases lifespan and improves muscle function in dystrophic dystrophin/utrophin-deficient mice. Mol Ther. 2008; 16:1539-45. [PubMed: 18665159] 


\section{Article Highlights}

- Gene therapy represents a promising approach for treating both Duchenne and Becker muscular dystrophy (DMD/BMD).

- The most direct approach to treating this disease would be to restore dystrophin production in muscle.

- Vectors derived from adeno-associated virus (AAV) have been shown capable of delivering new genes body wide in adult mammals

- AAV vectors have a small carrying capacity, such that gene therapy of DMD/BMD requires the use of micro-dystrophin cDNAs

- Current efforts to bring AAV/microdystrophin into the clinic will require careful monitoring of immune responses to the vector or transgene as well as the potential for readministration of vector after several years 
a

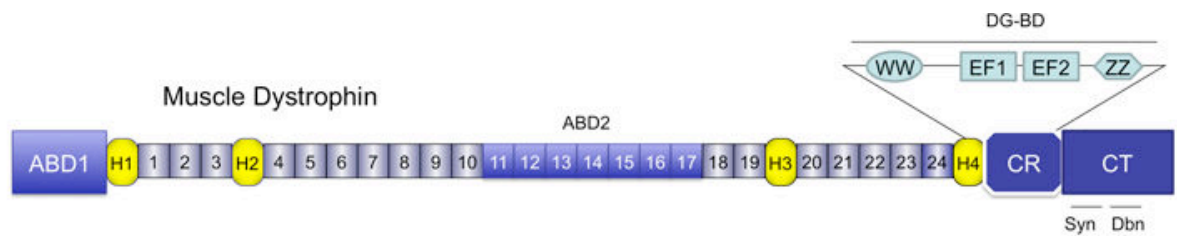

Micro-Dys

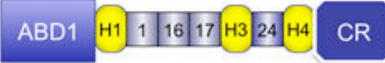

CT

b

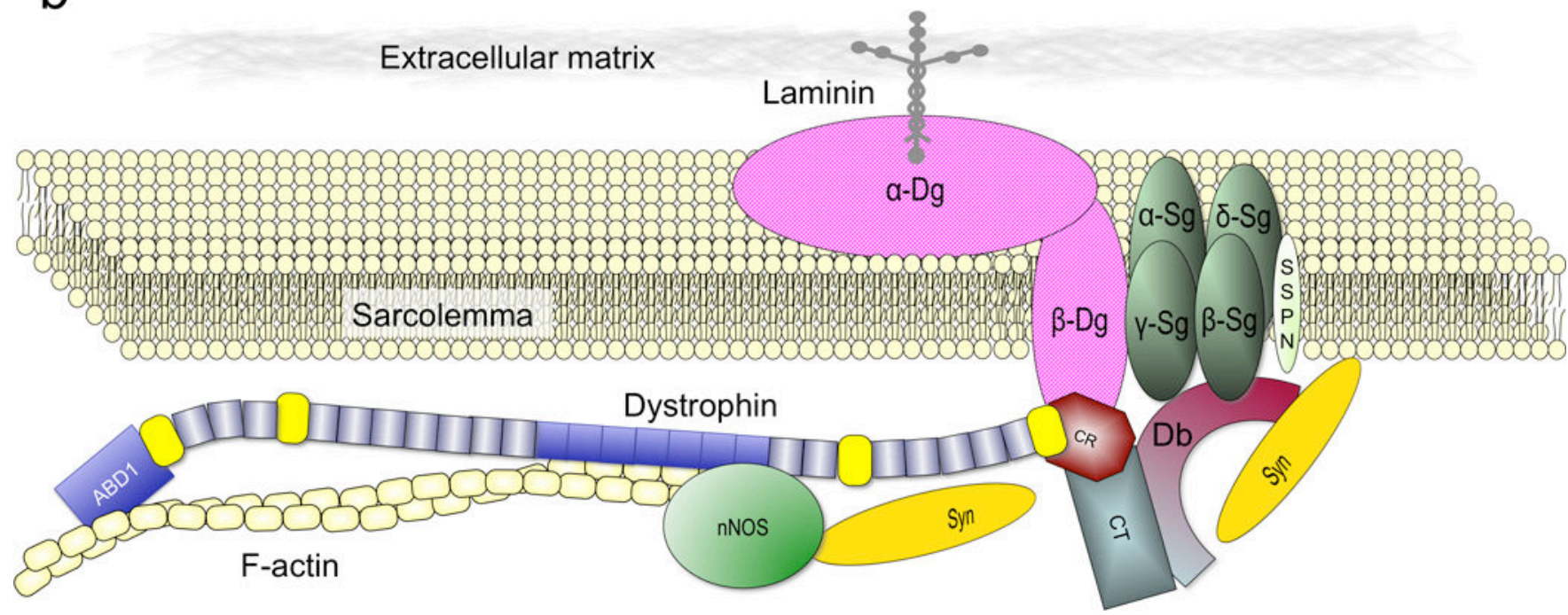

Figure 1. Model of dystrophin and the dystrophin-glycoprotein complex (DGC) in skeletal muscle

Dystrophin establishes a structural link between the intracellular cytoskeleton and the extracellular matrix that provides mechanical stability to the muscle sarcolemma by facilitating the lateral transmission of forces developed during muscle contraction.

Dystrophin and the DGC also serve as a scaffold for signaling proteins that help maintain muscle homeostasis. This simplified illustration depicts the major DGC components. Dg, dystroglycan; F-actin, filamentous $\gamma$-actin; nNOS, neuronal nitric oxide; $\mathrm{Sg}$, sarcoglycans; nNOS, neuronal nitric oxide synthase; Syn, syntrophins; SS, sarcospan. 


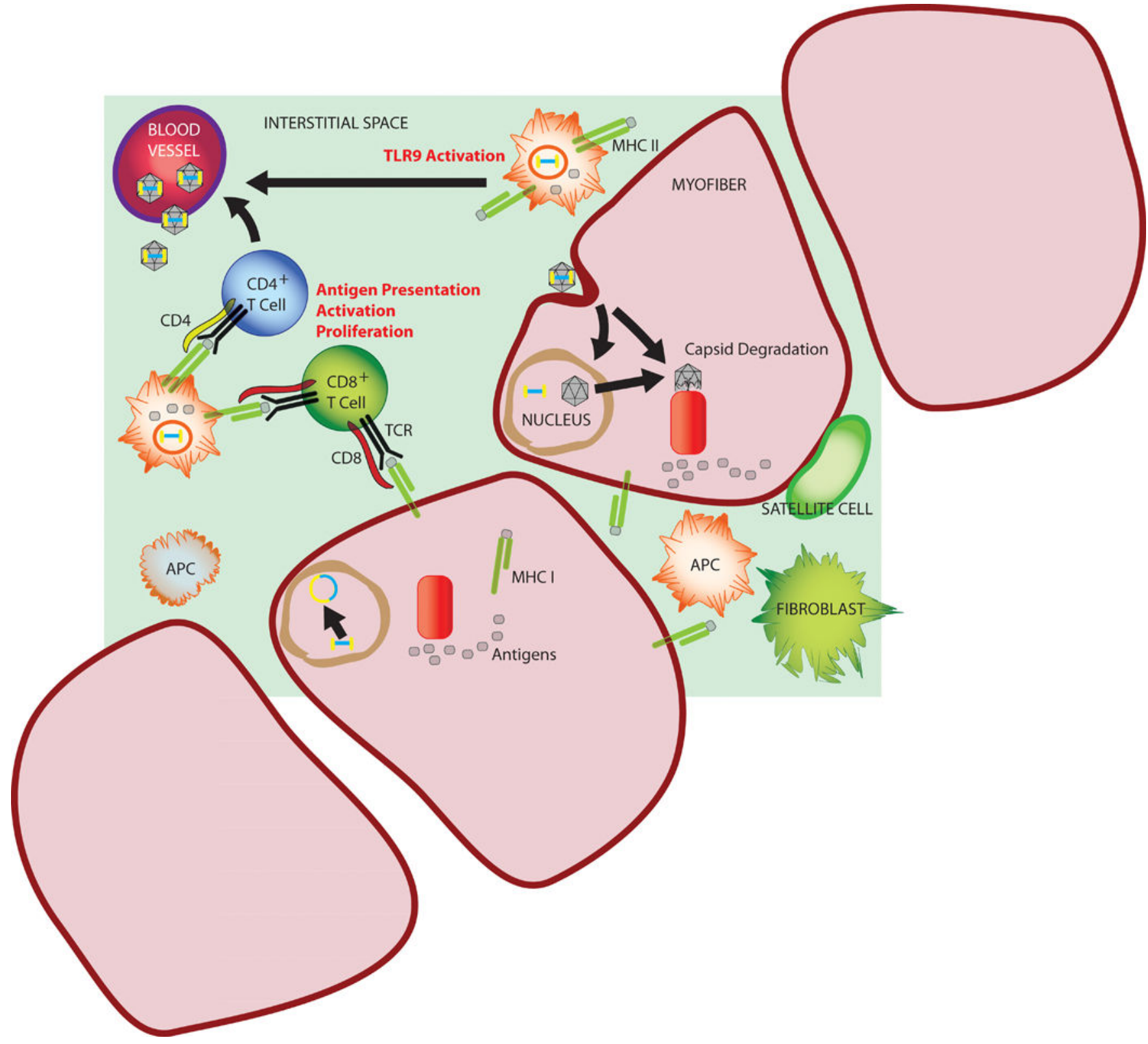

Figure 2. AAV Muscle Transduction

AAV capsids can reach striated muscle through by extravasation after intravenous delivery. Within this tissue are professional antigen-presenting cells (APCs), which reside in low numbers in healthy muscle. However, their numbers can be increased through proliferation of resident cells or through recruitment from circulation, as in the case of chronic damage that occurs in muscular dystrophy. Multiple AAV serotypes not only exhibit tropism for myogenic cells, such as myofibers of skeletal muscle, but for non-target cells as well including APCs. Innate immunity can derive from a TLR9-activated response to the vector genome or through presentation of capsid and/or transgene antigens by transduced cells. Lymphoid $\mathrm{T}$ cells become activated, proliferate and may amplify the immune response through adaptive immunity and CTL-mediated response. 


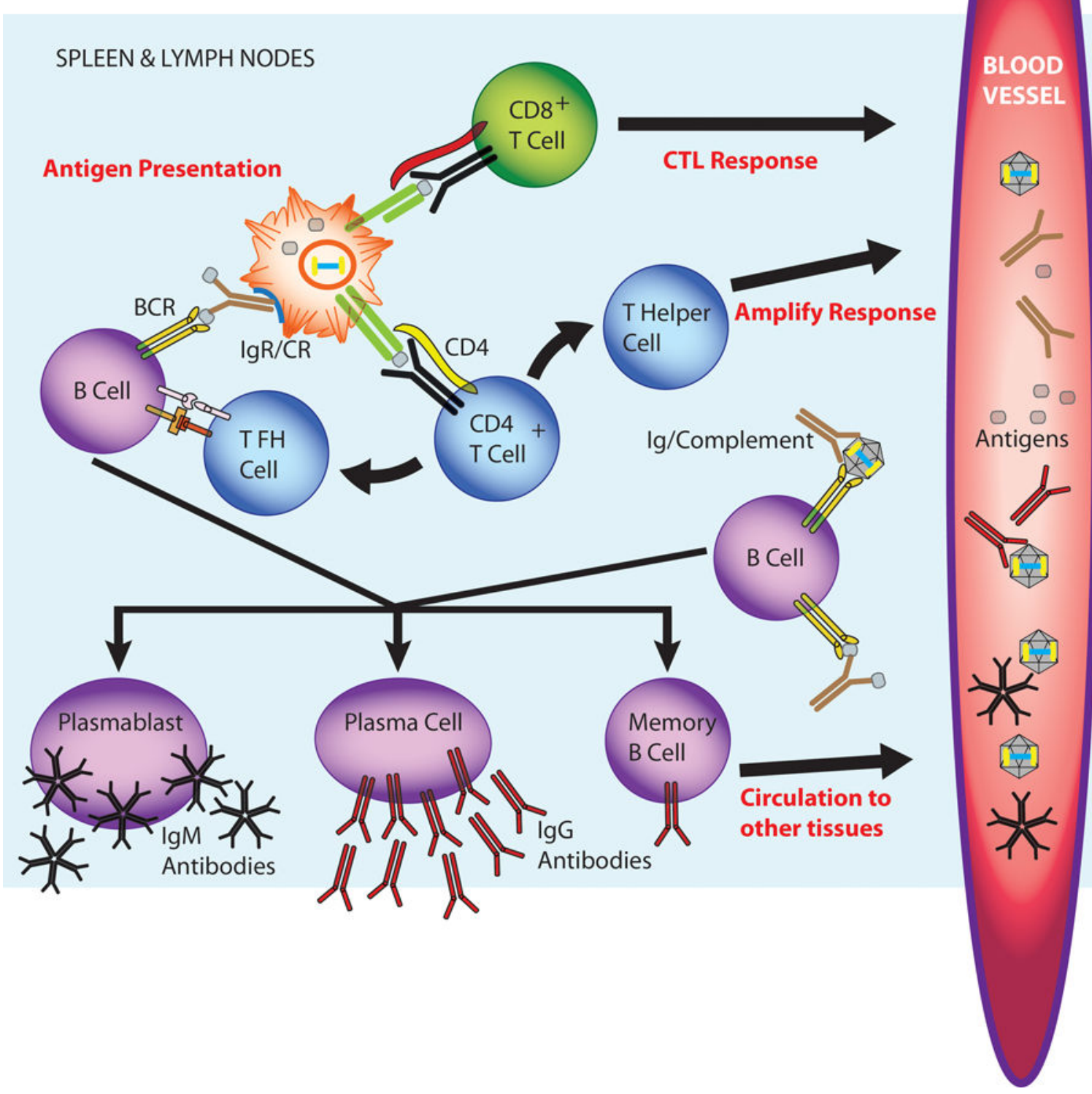

Figure 3. AAV and Lymphoid Tissue

After intravenous delivery of AAV vector, the transducing activity of the capsid can be neutralized by various factors in circulation. Complement proteins may bind to AAV antigens, either from intact or degraded capsids, and activate the complement system. Preexisting immunoglobulins (Ig) raised from previous AAV exposure may exhibit crossreactivity to other serotypes. Once bound to the $\operatorname{Ig}$ receptor $(\mathrm{IgR})$ or complement receptor (CR) of an APC, the antigen can be presented to the B cell receptor (BCR). With costimulation from a $\mathrm{T}$ follicle helper $(\mathrm{T} \mathrm{FH})$ cell, the $\mathrm{B}$ cell will differentiate to produce $\mathrm{Ig}$ 
antibodies or enter circulation as a memory B cell. B cells can also become activated through cross-presentation with $\mathrm{CD} 4{ }^{+} \mathrm{T}$ cells that transition into $\mathrm{T}$ FH cells or directly by $\mathrm{Ig} /$ complement activation. In a similar manner within striated muscle, antigen presentation to $\mathrm{CD} 8^{+} \mathrm{T}$ cells can lead to a CTL-mediated response and an amplified immune response through $\mathrm{CD}^{+} \mathrm{T}$ cells that differentiate into $\mathrm{T}$ helper cell subsets. 